\title{
Entre la redención y la ruta de la inclusión. Intervenciones tratamentales de actores no estatales en cárceles bonaerenses*
}

DOI: https://doi.org/10.18046/recs.i32.4026

\author{
Between Redemption and the Path of Inclusion. Treatment \\ Interventions by Non-state Actors in Buenos Aires Prisons
}

Andrea Natalia Lombraña ${ }^{* *}$

CONICET-IDAES, Universidad Nacional de San Martín (Buenos Aires, Argentina)

Natalia Soledad Ojeda ${ }^{* * *}$

CONICET-IDAES, Universidad Nacional de San Martín (Buenos Aires, Argentina)

Carolina Emilia Di Próspero ${ }^{* * *}$

CONICET-IDAES, Universidad Nacional de San Martín (Buenos Aires, Argentina)

\section{María Belén Pepe ${ }^{* * * *}$}

CONICET-IDAES, Universidad Nacional de San Martín (Buenos Aires, Argentina)

\footnotetext{
* Este artículo se deriva del proyecto "Dispositivos de transición a la libertad: un abordaje etnográfico sobre políticas públicas en seguridad ciudadana e inclusión social pospenitenciaria del área metropolitana de Buenos Aires". Es dirigido por la Dra. Natalia Ojeda y financiado por el Fondo de Investigación Científica y Tecnológica (FONCYT) de la Agencia Nacional de Promoción Científica y Tecnológica, dependiente del Ministerio de Ciencia, Tecnología e Innovación Productiva de Argentina. Artículo de investigación recibido el 13.05.2020 y aceptado el 21.07.2020.

** Doctora en Antropología Social de la Universidad de Buenos Aires. Profesora de nivel medio y superior en Ciencias Antropológicas de la Universidad de Buenos Aires; investigadora asistente del Consejo Nacional de Investigaciones Científicas y Técnicas de Argentina (CONICET) en el Instituto de Altos Estudios Sociales, donde también coordina el Núcleo de Estudios Socioculturales sobre el Derecho y sus Instituciones (NESDI); integrante del grupo responsable del proyecto "Dispositivos de transición a la libertad: un abordaje etnográfico sobre políticas públicas en seguridad ciudadana e inclusión social pospenitenciaria del área metropolitana de Buenos Aires" (PICToo67-16) del FONCYT. Correo electrónico: andrealombrana@conicet.gov.ar ORCID: https://orcid.org/oooo-0oo3-2973-0376
} 
*** Doctora en Antropología Social por el Instituto de Altos Estudios Sociales de la Universidad Nacional de San Martín (Argentina). Investigadora adjunta del CONICET e integra el equipo de gestión del CUSAM, ubicado dentro del Complejo Penitenciario Conurbano Norte, donde también se desempeña como docente. Correo electrónico: natalyaojeda@gmail. com.ar ORCID: https://orcid.org/oooo-ooo1-9287-6592

**** Doctora en Antropología Social por la UNSAM y becaria postdoctoral CONICET; investigadora asociada en el Instituto de Altos Estudios Sociales (IDAES) de la Universidad Nacional de San Martín (Argentina), donde también se desempeña como docente adjunta, e investigadora en el Núcleo de Estudios Socioculturales sobre el Derecho y sus Instituciones (NESDI-IDAES) y en el Observatorio Interuniversitario de Educación, Tecnología y Sociedad (UNSAM-UNPAZ-UNIPE). Correo electrónico: cdiprospero@unsam.edu.ar ORCID: https://orcid.org/oooo-ooo2-9604-6155

***** Antropóloga por la Universidad de Buenos Aires y becaria doctoral CONICET con sede en el IDAES; integra el equipo de gestión del CUSAM, ubicado dentro del Complejo Penitenciario Conurbano Norte, donde también se desempeña como docente. Correo electrónico: mbpepe@conicet.gov.ar ORCID: https://orcid.org/oooo-0002-0588-8032

\section{Cómo citar/How to cite}

Lombraña, Andrea Natalia; Ojeda, Natalia Soledad; Di Próspero, Carolina Emilia; Pepe, María Belén (2020). Entre la redención y la ruta de la inclusión. Intervenciones tratamentales de actores no estatales en cárceles bonaerenses. Revista CS, 32, 131-161. https://doi.

org/10.18046/recs.i32.4026 


\section{Resumen}

El artículo propone pensar la relación entre actores estatales y no estatales en las cárceles de la Provincia de Buenos Aires (Argentina), a través del análisis de la intervención de dos organizaciones de la sociedad civil: La Fundación y La Red, que despliegan propuestas integrales ligadas al deporte, la educación, la religión y el trabajo. Se identifica cómo se disputan amplios repertorios de acción que operan más allá de la formalidad del Estado, poniendo la atención sobre los lugares de ruptura y negociación. Desde esta perspectiva, abordamos el campo bajo estudio como margen, en tanto se pone en cuestión una visión Estado-céntrica del orden social para abordar las prácticas y los discursos ligados al diseño y control de propuestas de tratamiento, orientadas a la resocialización de las personas privadas de libertad.

\section{PALABRAS CLAVE:}

Estado, cárceles bonaerenses, tratamiento penitenciario, resocialización, actores no estatales

The aim of this article is to think on the relationship between state and non-state actors in the prisons of the Province of Buenos Aires (Argentina) by means of an analysis of the intervention of two civil society organizations: La Fundación (The Foundation) and La Red (The Network), whose proposals are linked to sport, education, religion, and work. We identified how wide action repertoires are disputed and operate beyond the formality of the state, while paying attention to rupture and negotiation places. From this perspective, we approach the field under study as a margin, while questioning a state-centered vision of the social order to address the practices and discourses linked to the design and control of treatment proposals aimed at the re-socialization of detainees.

\section{KEYWORDS:}

State, Buenos Aires Prison, Penitentiary Treatment, Re-socialization, Non-state Actors 



\section{Introducción}

Este artículo forma parte de una investigación más amplia que propone pensar la gestión de las cárceles de la Provincia de Buenos Aires (Argentina) como territorios donde conviven la agencia de actores estatales y no estatales en el ejercicio de la regulación del orden y el tratamiento penitenciario ${ }^{1}$. Desde esta perspectiva abordamos el campo de estudio como margen del Estado (Das; Poole, 2008), orientado por una estrategia analítica y descriptiva que pone en cuestión una visión Estado-céntrica del orden social.

Por la propia forma en la cual se ha ido constituyendo la agencia penitenciaria bonaerense, sostenida institucionalmente sobre la delegación de sus funciones principales, identificamos cómo se negocian amplios repertorios de acción con actores que operan más allá de la formalidad del Estado. En estos márgenes se construyen y sustentan el desarrollo y la organización de la vida cotidiana en las cárceles provinciales: se proveen recursos materiales (comida, vestimenta, elementos de higiene y cuidado personal, medicamentos, entre otros insumos necesarios), se gestiona el control y la seguridad, se llevan adelante actividades de formación, deportivas, recreativas y espirituales, se establecen mecanismos de resolución de conflictos y rutinas, se construyen comunidades de práctica y referentes de grupo, y se ofrecen servicios de inclusión social tanto dentro como fuera de los muros de la cárcel.

Abrams (1988) advierte sobre los riesgos de reificar al Estado en los estudios dedicados a abordarlo y propone prestar mayor atención a los sentidos en los cuales el "Estado no existe", sugiriendo que cualquier investigador que quisiera abordarlo debería concentrar sus esfuerzos en dar cuenta de la principal actividad en la que el Estado se ve involucrado: la legitimación de lo ilegítimo. Siguiendo esta propuesta, nuestra perspectiva teórica plantea como punto de entrada al análisis aquellas áreas donde el Estado no logra elaborar un marco discursivo común; es decir, un enfoque que permite poner en tensión la idea del "Estado como máquina de fabricación de consenso" (Roseberry, 1994: 134), poniendo más bien la atención sobre los lugares de ruptura y negociación.

El objetivo del presente trabajo es analizar las prácticas y los discursos ligados al diseño y control de propuestas de tratamiento, orientadas a la resocialización de las personas privadas de libertad, a partir de dar cuenta del impacto que provoca la participación de dos organizaciones de la sociedad civil en un establecimiento del Servicio Penitenciario Bonaerense (SPB).

1. A lo largo del articulo utilizamos cursivas para referirnos a las categorías de uso nativo. 


\section{Metodología}

Consideramos productivo, entonces, un diseño de investigación que se concentra en el seguimiento de los actores, privilegiando el análisis del funcionamiento de las instituciones y las prácticas de los agentes y otros actores involucrados en el campo penitenciario. En este sentido, adoptamos la perspectiva antropológica, capaz de ofrecer conocimientos diferentes a los aportados por otras disciplinas que tradicionalmente lo ha estudiado. Su particularidad radica en el desarrollo de etnografías concentradas en "localizaciones cambiantes" (Ferguson; Gupta, 2002); que se construyen estableciendo "zonas de contacto" (Pratt, 1992) y "afiliaciones tácticas" co los "otros", resultando en una perspectiva multisituada que permite dar cuenta de los desplazamientos dentro del discurso y el espacio social (Clifford, 1999).

En este caso, llevamos adelante distintas actividades de trabajo de campo en tres unidades penales ubicadas en una localidad del conurbano bonaerense que integran un complejo penitenciario modelo dentro del sistema ${ }^{2}$; dos de ellas son mixtas, una es ocupada exclusivamente por varones y, en conjunto, presentan regímenes de alojamiento de distintos tipos: cerrado, de modalidad atenuada para procesados, moderada para penados y abierta para quienes están próximos a recuperar la libertad. La mayoría de las personas allí detenidas provienen de los barrios populares aledaños al penal o de áreas cercanas, y lo mismo ocurre con los trabajadores que allí se desempeñan, resultando la paradoja de que algunos detenidos y penitenciarios se reencuentran en un espacio carcelario luego de haber sido vecinos.

Cabe mencionar que nuestro acceso al campo se da en la convergencia de diferentes roles: como parte del equipo de gestión del Centro Universitario emplazado en una de las unidades del complejo, como docentes del mismo centro y como investigadoras. El desarrollo de estas tres actividades nos facilita el acercamiento cotidiano, no solo a la observación de las problemáticas bajo estudio, sino a la interacción con los diferentes actores sociales involucrados, sus realidades, inquietudes, tensiones; en suma, a sus diversas estrategias de agenciamiento en la complejidad del contexto carcelario.

2. El complejo penitenciario en cuestión se emplaza en la zona norte del área metropolitana de Buenos Aires. Los datos que permiten identificar este establecimiento y los actores que lo transitan son reservados y han sido modificados por tratarse de información sensible; no hacerlo podría colisionar con el derecho a la integridad personal y la incolumidad del sujeto de investigación. Consideramos entonces que a los fines de este estudio "importan sus acciones en relación al lugar estructural que ocupan en una determinada red de relaciones institucionales (...). Además porque la forma en que actuaron (...) es una forma de actuación regular" (Tiscornia, 2008: 12). En muchos casos, tampoco aparecen, o aparecen modificados, los lugares y las fechas de los acontecimientos relatados, ya que consideramos suficiente conocer de su existencia en este caso (Martínez, 2004). 
La investigación combina la observación de tipo participante en distintos espacios del establecimiento penitenciario, con la realización de entrevistas semiestructuradas a funcionarios del poder ejecutivo y judicial, personal penitenciario, personas privadas de la libertad, profesionales y voluntarios de la sociedad civil que ingresan a las unidades para desarrollar distintas actividades. Estos últimos suelen acercarse al Centro Universitario en el que trabajamos con diferentes intereses: sumar apoyo o adeptos a sus fundaciones, invitar a la gestión del centro a participar de sus redes y actividades, conocer el espacio en el que gran parte de sus beneficiarios/as estudian, entre otros. En el marco de estas circunstancias, realizamos entrevistas y mantuvimos charlas informales con referentes de organizaciones de la sociedad civil mencionados en este trabajo (reuniones en sus oficinas, pero también en los pasillos del Centro Universitario, durante la espera al ingreso a la unidad penal en puestos de control y puertas de acceso, en el estacionamiento del complejo, etc.). Sin este tipo de interacción construida en la cotidianidad del transitar el complejo carcelario, no sería posible el análisis de otro tipo de datos, como los recolectados en forma digital.

En ese sentido, hemos desarrollado un abordaje etnográfico de material obtenido en redes sociales y plataformas digitales oficiales de estas organizaciones bajo análisis. Vale destacar que, en la actualidad, casi cualquier objeto de estudio de las ciencias sociales está, de uno u otro modo, alcanzado por internet, ya que esta permea prácticamente todos los ámbitos de la vida social, personal y colectiva (Gómez-Cruz; Ardèvol, 2013: 194). Apelando a nuevas formas de construir el campo, incorporamos el quehacer de las etnografías de lo digital, cuyo propósito es etnografiar el mundo contemporáneo atravesado por lo digital en diferentes aspectos y formas. En este artículo se evidencia que no podemos obviar la construcción de comunidades que las asociaciones de la sociedad civil realizan también a través de sus sitios web y plataformas de contenidos digitales (Di Próspero, 2017).

Finalmente, entendemos que lo público no es un organismo social o político, y tampoco monopolio exclusivo del Estado, sino más bien una forma de vida colectiva que emerge alrededor de un problema, siendo al mismo tiempo parte de él (Cefaï, 2003). Las implicancias metodológicas de esta forma de hacer investigación social desplazan la figura del investigador como intérprete privilegiado de los procesos sociales, como el único capaz de develar los mecanismos que hacen funcionar a la sociedad, y lo ubican como un agente más en las disputas por el sentido de las acciones. Reconociendo que cada uno de ellos tiene saberes prácticos y capacidades de evaluación para cada situación -a través de las cuales pueden ajustarse a la misma o bien criticarla-, no se tratará aquí de develar lo que se encuentra detrás de las estructuras sociales mediante la operación crítica de las investigadoras, sino que, por el contrario, se intentará "poner en valor" los sentidos que los propios agentes 
sociales producen "en situación” (Corcuff, 1998) para hablar, a través de ellos, del campo bajo análisis.

\section{Resultados}

En su Ley Orgánica de 1978, el Servicio Penitenciario Bonaerense (agencia a cargo de la custodia y tratamiento de todas las personas privadas de libertad en los establecimientos carcelarios de la Provincia de Buenos Aires) se presenta como una "fuerza de seguridad que contribuye al mantenimiento del orden público y colabora con la obtención de la paz social". Sin embargo, el trabajo de campo en el complejo penitenciario mencionado pone en cuestión ciertos criterios que asocian las fuerzas de seguridad a un orden militarizado, jerárquico y verticalista ${ }^{3}$. Para comprender este fenómeno, nos remontamos a la creación, en el año 1877, de la Penitenciaría Nacional, inspirada en la prisión industrial inglesa de Pentonville que adoptó el reglamento disciplinario de Auburn: silencio total, aislamiento nocturno y trabajo en común en talleres durante el día (Caimari, 2004: 51).

Sin embargo, como señala Yangilevich (2017:170), tal complejidad y sofisticación no alcanzaron a las cárceles que se erigieron en la provincia de Buenos Aires: "los más modestos edificios carcelarios construidos en paralelo al interior del territorio bonaerense buscaron mantener tales principios. Sin embargo, estuvieron lejos de alcanzar la relevancia de la cárcel porteña. En parte porque a diferencia de ésta que reemplazó al cabildo como espacio de encierro y produjo un corte -o lo intentó-en la aplicación del castigo penal, el resto de las cárceles provinciales tuvieron un derrotero menos espectacular y más atado a la administración de justicia criminal a la que incluso precedieron". Sobre la infraestructura de las cárceles bonaerenses, la misma autora informa que los edificios eran precarios, dado que no fueron diseñados para cumplir con las funciones de encierro: no contaban con elementos para tal fin, tenían escasez de presupuesto, baja formación de sus agentes -que tampoco contaban con uniformes adecuados-entre otros muchos aspectos, que continuaron hasta entrado el siglo XX.

Es recién en el año 1937, según información oficial del SPB, que las cárceles bajo su jurisdicción dejaron de tener dependencia directa del poder judicial para comenzar a responder al ámbito del poder ejecutivo. Sin embargo, las problemáticas mencionadas no encontraron respuesta a partir de este cambio e, incluso, en su gran mayoría, aún permanecen sin resolución. Desde un análisis político

3. Características estas que sí hemos observado, por ejemplo, en el Servicio Penitenciario Federal argentino. 
funcional, el SPB y sus agentes presentan un comportamiento que por el momento podríamos llamar, de modo insuficiente, inorgánico. Los actores penitenciarios no se inscriben en un marco referencial que debería funcionar en forma vertical de acuerdo a la reglamentación vigente. Esta situación también se expresa en un alto nivel de informalidad administrativa y burocrática para el abordaje de las cuestiones cotidianas. Por ejemplo, autoridades que se niegan a cumplir con normas básicas que rigen formalmente en la administración: contestar notas, notificar por escrito, recibir oficialmente pedidos de audiencia, cumplir con resoluciones de jefatura del SPB y del poder judicial, redactar informes, efectivizar traslados de detenidos o emitir partes disciplinarios, etc. (Lombraña; Ojeda; Nogueira, 2019).

Así es como cada penal tiene sus propias reglas. Por eso, cada jefe de penal ${ }^{4}$, si bien se encuentra subordinado jerárquicamente al director, dicta su propia política para organizar la vida cotidiana de la prisión a su cargo. Por ejemplo, decide de forma independiente si sancionar o no a un detenido que comete una falta, incluso si deja registro de esto, según lo indica el código de faltas disciplinarias de internos, o si aplica una sanción informal; decide si su política es más bien dialoguista y de apertura o, por el contrario, si se define en el engome ${ }^{5}$. Así, para una misma cárcel hay jefes de penal que se muestran más abiertos a la posibilidad de otorgar espacios para la circulación interna de los detenidos u otorgan más tiempo para que los mismos desarrollen actividades educativas, recreativas, espirituales o bien promueven visitas desde el exterior de instituciones que participan de estas tareas. Por el contrario, hay jefes de penal que optan por el engome como política generalizada para aquello de definen como su cárcel. El jefe de penal va manejando su relación con los detenidos, tejiendo alianzas o estableciendo conflictos según dictan sus intereses. Estas prácticas dificultan alcanzar una eficiente organización funcional de la unidad penal y ubica en una situación de mayor vulneración de derechos a las personas detenidas, frente a la ampliación de márgenes de discrecionalidad y arbitrariedad en la resolución de cuestiones de la vida cotidiana y de la propia ejecución de la pena.

Ahora bien, la disposición de estas acciones dentro de la institución no debe interpretarse como una falla o una incoherencia del SPB, sino que es constitutiva de su funcionamiento. Si bien se ha tendido a abordar las estructuras estatales -y en particular a las agencias penitenciarias- como formas administrativas de organización política a cargo del control unívoco y centralizado sobre un determinado territorio o bien como órdenes burocrático-racionalizados (Weber, 1996), en este

4. Funcionario perteneciente al SPB encargado de la seguridad interna del penal.

5. Categoría nativa que refiere a una política de gestión de seguridad interna caracterizada por la restricción de la circulación de las personas detenidas a espacios reducidos. 
trabajo intentamos superar estas visiones restrictivas y, en su lugar, proponemos analizarlas como realidades que se construyen en procesos de producción sociocultural. Siguiendo a Das y Poole (2008: 34), buscar al Estado en aquellos lugares "en los que el derecho estatal y el orden deben ser constantemente restablecidos (...) en lugar de privilegiar las formas de razonamiento metafísico en la manera de entender la soberanía".

Es extensa la tradición teórica y la agenda investigativa, dentro del campo de los estudios de las prisiones, que han concentrado sus reflexiones en torno a la gobernabilidad y el orden del espacio carcelario (Chauvenet, 2006; Clemmer, 1968; Goffman, 2001; Sykes, 2017). Para América Latina, consideramos los aportes de Jorge Núñez (2007) sobre la existencia de prácticas de autogestión en las cárceles ecuatorianas. Cerbini (2012) también las registra en la cárcel de San Pedro (Bolivia), donde los reclusos gestionan aspectos de su vida como comida, pensiones y restaurantes. En Venezuela, Antillano (2015) describe una cárcel controlada por los propios internos, adhiriendo a conceptualizar esta situación como estructura de autogobierno que sirve a los efectos de preservar el orden interno, enfrentar amenazas externas y proveer medios para la vida colectiva. En Brasil hay una extensa producción que pone en el centro del análisis la autogestión de los internos como un reflejo de las jerarquías, la organización y las disputas al interior de las facciones dedicadas al tráfico de drogas en las favelas (Barbosa, 2005; Biondi, 2018; Darke, 2013; Nunes, 2011).

En el ámbito local, distintos autores han estudiado este fenómeno en el contexto de las cárceles bonaerenses. Miguez pone en discusión la relación de extrema alteridad que suele atribuirse al vínculo entre penitenciarios e internos; e identifica, en su lugar, una variedad de mecanismos de reciprocidad. A partir de la recuperación democrática, las modalidades para lograr obediencia dentro de las prisiones son sostenidas por un sistema complejo de intercambios, que no siempre están regulados por el código legal. La amenaza latente de generar conflictos por parte de las personas detenidas introduce "balances de poder situacionalmente cambiantes" (Miguez 2007: 155) que imponen a los agentes encargados de la seguridad, el despliegue de diversas estrategias de producción de orden: castigar a los delincuentes (imposición de violencia física), participar de la delincuencia (puesta en juego de códigos y valores consuetudinarios de la subcultura delictiva) o regular los conflictos (negociaciones a través de interlocutores específicos). Todo esto define vínculos inestables, complejos y cambiantes que adquieren formas coyunturales en los cuales se disponen influencias interpersonales y códigos de conducta signados por las condiciones en las que tienen lugar (Miguez, 2007).

Daroqui (2014) apela a los conceptos de estrategia, técnica y tecnología foucaultianos, ampliando los alcances analíticos de la noción de poder más allá de su 
definición jurídica, de modo que sea posible incluir en su órbita los mecanismos o procedimientos concretos a través de los cuales se ejercita efectivamente. Desde allí advierte cómo esta agencia penitenciaria confiere a determinados detenidos la organización de las relaciones intramuros y la gestión de la población, con distintos grados de formalización y estabilidad, según las particularidades específicas que adquiere el vínculo en cada espacio carcelario. Menciona como las menos estructuradas a aquellas relacionadas con la delegación de la violencia física directa, cuya finalidad inmediata es la de infringir un daño puntual (que puede incluir la muerte) a pares detenidos. Luego existen formas de organización intermedia que establecen alianzas más complejas a través de la figura del/la limpieza ${ }^{6}$, en quien se delega el ejercicio de la violencia y el sostenimiento de un determinado orden en un territorio específico durante un período de tiempo. Los regímenes evangelista-penitenciarios, por último, constituyen el entramado más complejo de tercerización del orden; en el cual se deja en manos del ministerio (jerarquía eclesiástica integrada por un grupo reducido de personas detenidas) la formulación y administración de un régimen de vida disciplinario para el conjunto de aquellos alojados en los pabellones de hermanitos ${ }^{7}$. En cualquier caso, según la lectura de Daroqui (2014), quienes establecen los límites de este cogobierno son siempre los agentes penitenciarios; son ellos, exclusivamente, quienes conservan la potestad de modificar o incluso terminar, en cualquier momento, los acuerdos delegatorios más o menos explícitos.

Gual (2016), en su estudio sobre dos prisiones federales de máxima seguridad para varones adultos, concluye que no es posible encasillar este régimen penitenciario como absolutamente correccionalista ni como completamente segregacionista.

6. El/la limpieza funciona como una suerte de referente tanto para las personas detenidas como para los agentes encargados de su custodia y tratamiento en los penales bonaerenses, siempre en relación a un espacio determinado y a un marco de acción bien específico. En términos generales, existen aquellos que regulan el orden de los pabellones (ámbitos de alojamiento), de la cancha (espacio de desarrollo de actividades recreativas, deportivas y sociales dentro de los establecimientos de detención) y de la visita (salones y espacios relacionados con la recepción de familiares y allegados). Sin embargo, las funciones del/la limpieza no se limitan a intermediar entre presos y guardiacárceles ni tampoco a regular el ejercicio de la violencia en sus territorios, sino que, además, resultan vitales en la organización del sistema de intercambios de objetos que sostienen la vida intramuros (Ángel, 2015). Ser limpieza no es tampoco una posición estable, sino que es puesta a prueba constantemente tanto por parte de los otros presos como por el propio SPB. Tal y como señala Miguez (2008: 146), "estos privilegios no están exentos de responsabilidades, ya que ocupar esa posición implica contraer múltiples obligaciones que deben ser cumplidas para mantener el prestigio con el que se llegó a ella en primer lugar”.

7. Concepto nativo para referirse a los espacios de alojamiento de detenidos donde se practica el culto evangélico. Sobre la trama de relaciones en torno a la configuración del orden en prisión a partir de la inserción del evangelismo en cárceles de Argentina puede consultarse: Andersen (2012), Brardinelli y Algranti (2013), Manchado (2015) y Rosas (2015). 
Reconoce en su lugar un carácter híbrido de economía mixta; donde la agencia penitenciaria gestiona a través de la violencia, el aislamiento, la amenaza y la imposición de castigos, pero, simultáneamente, habilita espacios, situaciones y circulación de bienes y servicios que responden a la "lógica de funcionamiento afín a un orden negociado" (Gual, 2016: 321).

Con todo, las prácticas de control y seguridad en las cárceles de la provincia parecieran disponer de cierta ampliación en los márgenes de agencia de las personas detenidas (Galvani, 2010; Nogueira, 2015). Sin embargo, esta modalidad de gestión produce un estado de incertidumbre permanente y un clima de conflictividad latente, bajo un aparente equilibrio en la cotidianidad de la cárcel.

Ahora bien, dentro del vasto corpus de estudios que se han ocupado de analizar estos márgenes, casi no ha sido indagado uno de los aspectos centrales que justifican la existencia misma de las prisiones modernas: el conjunto de dispositivos que despliegan -en paralelo con las prácticas de control y seguridad antes descritas-en la búsqueda de alcanzar la resocialización de las personas prisionalizadas. En su gran mayoría, las investigaciones locales -siguiendo los lineamientos de la sociología anglosajona (Garland, 2005) y la nueva penología (Feely; Simon, 1995)- han contribuido a la idea de que el funcionamiento concreto del sistema carcelario contemporáneo, habiendo fracasado en esta función original, responde más bien a la contención de los riesgos durante el período de encierro que a la transformación subjetiva de la persona detenida (Sozzo, 2007); cobrando mayor relevancia en los últimos tiempos los estudios sobre el regreso a la comunidad y las posibilidades de inclusión una vez recuperada la libertad, fuertemente influenciados por los trabajos producidos desde y sobre el norte global (Beckett; Sasson, 2004; Brandariz-García; Castro-Liñares, 2014; Western, 2006).

Tal vez esa tendencia explique la poca atención que ha recibido en sí mismo el aspecto tratamental de la prisión -sobre todo en los estudios de corte empírico- $y$ la escasa discusión experta en torno a los alcances efectivos del ideal resocializador en Argentina, en comparación con la fuerte presencia que ambos elementos tienen dentro los discursos de los actores que viven diariamente la cárcel. En este sentido, deben destacarse los trabajos de Mouzo (2014), quien, advirtiendo la falta de análisis sistemático en este punto, ha llevado adelante un trabajo de indagación específica sobre los diversos sentidos de la resocialización a través del abordaje de algunos programas desarrollados en cárceles federales, como la Metodología Pedagógica Socializadora (Mouzo, 2014) o el Programa Interministerial de Salud Mental Argentino (Mouzo; Ríos, 2018). 
En esta línea, abordamos en términos de $c a s o^{8}$ dos experiencias tratamentales dentro de un establecimiento bonaerense que, llamativamente, son llevadas adelante por organizaciones de la sociedad civil: La Fundación y La Red. Desde nuestra lectura, ambas se establecen como "sitios de práctica" en donde la ley y otras acciones estatales son colonizadas mediante otras formas de regulación (Das; Poole, 2008). Allí se advierte -como se verá- el modo en que los límites entre el centro y la periferia, lo público y lo privado, lo legal y lo ilegal, son elaboraciones en permanente (re)configuración que intervienen tanto en el diseño, la implementación y la evaluación de las políticas de reinserción social. Los márgenes se mueven, en este aspecto también, tanto en el interior como fuera del Estado como supuesto necesario para su funcionamiento regular.

\section{“Ni un día antes": La Fundación}

La Fundación (LF) se define a sí misma como "una organización sin fines de lucro que se sustenta con el aporte de voluntarios y donantes. Buscamos bajar la tasa de reincidencia delictiva promoviendo la integración, socialización y acompañamiento de personas privadas de su libertad a través del rugby, la educación, el trabajo y la espiritualidad"9.

Según detalla, se dedica, desde el año 2009, a la enseñanza del rugby dentro del complejo penitenciario. En los últimos años, han expandido el proyecto en 65 unidades penales más. Comenzaron siendo diez jugadores y dos voluntarios, y actualmente cuentan con 649 voluntarios, 3030 jugadores en unidades de todo el país (en 21 provincias) y están asociados a 80 empresas empleadoras, con las que también dictan cursos de formación. LF propone una "formación completa" deportiva, educativa y espiritual, que "les permite empoderarse frente a la sociedad cuando recuperan la libertad, desde la independencia económica y la recuperación de la dignidad personal". El área de espiritualidad, por su parte, comprende "yoga y encuentros grupales para fortalecer el bienestar emocional".

8. Boltanski (2000) indica que la construcción del caso constituye una herramienta conceptual y metodológica sustentada en el reconocimiento de la acción social como situacional, cambiante, dinámica y ligada tanto a sujetos como a objetos. La atención no debe ponerse en la identidad o en las características presupuestas o predefinidas de las personas que realizan la acción, sino en la propia constitución y desarrollo del caso.

9. Esta información ha sido obtenida de la página oficial de LF. La información detallada sobre la fuente de algunas citas, así como de las imágenes, ha sido omitida para proteger la identidad de las personas o entidades. 
El sustento principal de la propuesta de LF se basa en la experiencia en el terreno a través de los años, que comenzó con la tarea de los primeros voluntarios de forma exploratoria. Identificaban, por entonces, a la población carcelaria con base en su peligrosidad; de acuerdo al relato de estos primeros voluntarios en un video motivacional de Connecting Ideas de 2016, la primera vez que fueron al penal pidieron que les trajeran detenidos del pabellón evangelista, ya que eran los más tranquilos, pero otros se enteraron y se sumaron al entrenamiento: "el que tenía más miedo no era mi amigo ni yo, sino el evangelista, parece que no se llevan muy bien [risas en todo el auditorio mientras el referente hace ademanes de temblar]. Llevamos 400 martes que ininterrumpidamente vamos a la unidad de máxima seguridad [ovación total del auditorio]".

Durante la exposición hay varios tramos emotivos y otros, como este que citamos, de contenido aparentemente humorístico, al comparar la figura del detenido perteneciente a un pabellón evangelista y uno perteneciente al de máxima seguridad. Aunque este último parece quedar mejor parado en el relato, la fortaleza que se destaca es la de los voluntarios, ya que entrenan a "los peores de todos". La exposición en Connecting Ideas continúa con una sucesión de retos alcanzados, paso a paso: "empezamos a derribar muros, primero con los evangelistas, los empezaron a aceptar. Después hicimos un partido contra la policía metropolitana”, más adelante con jueces de ejecución: “¿Por qué no hacemos un partido contra los jueces y los fiscales que los metieron presos? Fui a ver a los jueces, hicimos el partido". La exposición genera ovaciones y exclamaciones en el público. En los momentos de descripciones de los cuerpos y actitudes de los más rudos, también explotan las risas generalizadas, denotando el disfrute del espectáculo de choque de cuerpos musculosos en una arena romana. Las caras de asentimiento predominan, sobre todo cuando son resaltadas las cifras del éxito: "el nivel de violencia interna bajaba notablemente (...), la reincidencia en Provincia de Buenos Aires es del 65\%: de tres vuelven dos y por delitos más graves. La reincidencia entre quienes juegan al rugby es menor al $5 \%$ : de 500 personas, 450 salieron en libertad, volvieron diez: 290 delitos menos".

La puesta en escena tiene momentos de tensión, suspenso, miedo y distensión, anécdotas y un final feliz, ya que se muestra la LF desde su construcción misma, como una apuesta desopilante de trabajo con "presos de máxima seguridad" que termina convirtiéndose en una organización con una estructura sólida, objetivos claros y resultados concretos. Tratándose de una audiencia en su mayor parte del sector empresarial, todos estos elementos son relevantes de destacar a la hora de solicitar apoyo en forma de lugares de trabajo en blanco, donaciones, en suma: apoyo en sentido amplio, el cual permitió, al inicio, y hoy mantiene el crecimiento de La Fundación. 
Siendo una organización más de la sociedad civil que ingresa a la cárcel, La Fundación posee una característica que la diferencia respecto de otras: cuenta con el apoyo financiero del sector empresarial. Además, este empresariado adhiere a los principios incluidos en la llamada formación completa, no solo preocupada por el cuerpo (en términos deportivos), sino también por el alma: la espiritualidad de su sujeto social/objeto de su tratamiento, ya que apuntan a "los peores de todos". Durante el período de gobierno 2015-2019, incluso recibieron apoyo del Ministerio de Justicia, como explica uno de sus referentes: "empezamos a visitar cárceles del interior, el Ministerio de Justicia nos está acompañando, la Unión Argentina de Rugby (...) el rugby en realidad es una excusa".

\section{Segunda oportunidad}

LF se constituye en un dador de valores, reglas, normas y preceptos religiosos, además de ofrecer enseñanzas deportivas para las personas detenidas. Diversos testimonios de los integrantes de los equipos de LF, autodenominados "Gladiadores" ${ }^{10}$, hacen referencia a una serie de valores adquiridos a partir de su vínculo con la organización. Así, hablan de compañerismo: "en el pabellón de [Gladiadores] no te piden nada, al contrario, te regalan camisetas, botines, medias"; de sacrificio: "en la cancha, igual que en la vida"; de compromiso: "[Gladiadores] quiere decir cambio, estudio, compromiso. Comprometerse consigo mismo, con su familia y con los demás".

Ahora bien, el acceso a beneficios que conlleva pertenecer a LF supone también la contratación de una deuda, es decir que entre La Fundación y los rugbiers se establece un pacto de reciprocidad y compromiso que nace del agradecimiento por devenir beneficiarios de una segunda oportunidad: "Se nos ocurrió ir a ver al Papa, el Papa (...). La idea era que nosotros pagábamos nuestro pasaje y el de medio [gladiador], entonces empezaron a aparecer donaciones para hacer este viaje. La idea era poder dar segundas oportunidades".

Los integrantes del equipo participan activamente con su reciprocidad: "se empezó a rezar el rosario los días viernes, empezaron a pasar cosas inimaginables, la gente me decía: 'vos vas a rezar el viernes, ¿podés decirle a los [gladiadores] que recen por mi tía que tiene una operación?'. Tenemos una virgen del rugby, que es un pibe que le alcanza la pelota a la virgen".

10. El nombre del equipo ha sido cambiado a fin de mantener el anonimato, según se ha indicado anteriormente. 
FIGURA 1 La virgen del rugby

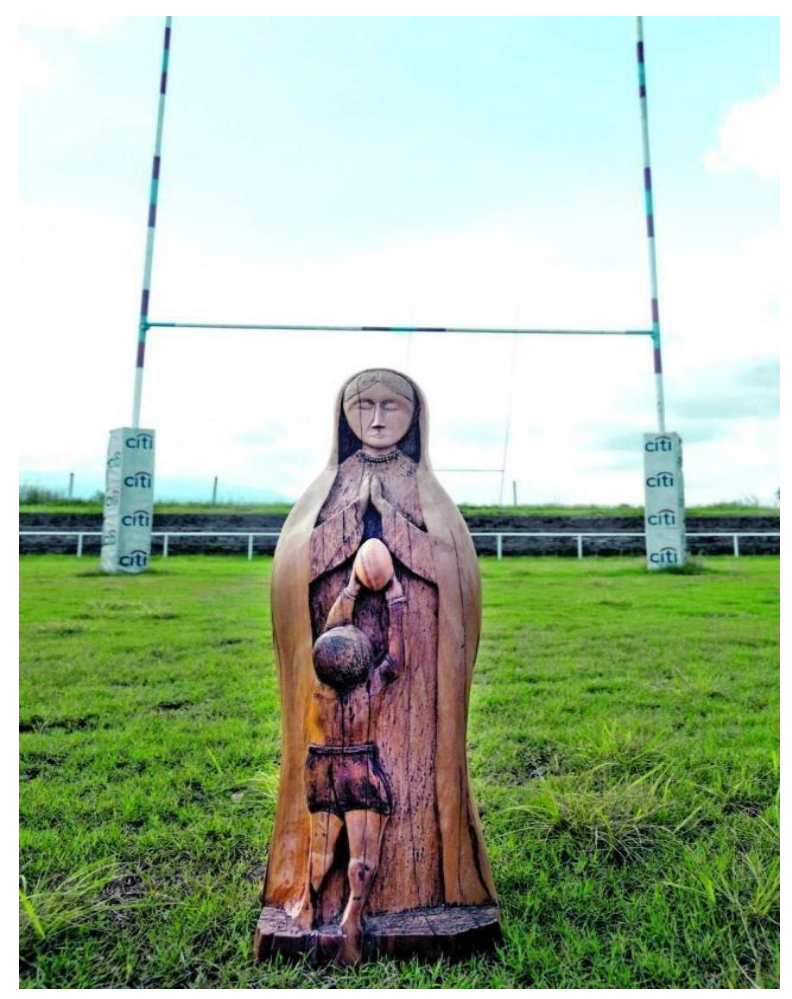

Fuente: Revista Valorar.

Tomar el compromiso implica hacer lo que haya que hacer, aunque no sea lo que se desee, como señalan los referentes al explicar que no a todos les gusta el rugby, pero lo practican porque LF es mucho más que rugby: "Al principio no les gustaba el deporte, después fueron cambiando la cara".

La segunda oportunidad ganada es agradecida cuantas veces sean necesarias. Como expresan algunos integrantes del equipo: "LF me dio la posibilidad de volver a vivir (...) descubrir esos valores que yo nunca tuve, ese amor de padre que nunca tuve, ese abrazo, esa confianza en mí (...) todo eso se lo debo a mi camiseta y hoy soy lo que soy gracias a [Gladiadores]”; "El rugby tiene valores lindos, que son el compañerismo, el sacrificio, que si te caés tenés que levantarte y seguir adelante porque si no perdés, nos enseña a ser mejores. Es como la vida, la vida nos golpea y tenemos que levantarnos y seguir adelante"; "Me ayudó mucho en mi persona, yo 
era una persona muy errónea y me ayudó un montón a cambiar, me ayudó con el tema de las adicciones, de la delincuencia".

Nopermanecer caído es el nombre del libro que reúne testimonios seleccionados de gladiadores. Esta sentencia se las compartió el Papa cuando fueron a verlo a Roma, él les relató que se trataba de un himno de los andinistas en el ascenso. En el video institucional, uno de los integrantes del equipo que fue a visitar al Papa recuerda: "el canto dice que en el arte de ascender lo importante no es caerse sino no permanecer caído. En el rugby, si te quedás en el piso perdés como en la guerra”.

Según los relatos recabados, la vida antes del rugby era deficitaria en todos los aspectos, y se trata de seres diferentes, definidos a partir de la falta. La Fundación llena entonces ese vacío con contenidos del orden civilizatorio que esta provee a modo de sacramento: a partir de acatar las reglas del pabellón de Gladiadores se pasa a ser una persona de bien, pero que aún debe pagar por el mal que hizo en el pasado. Esta concepción de la persona está en línea con la Teoría Evolucionista de fines del siglo XIX ${ }^{11}$, la cual sostiene que los seres que no poseen las características que definen a las llamadas sociedades complejas son considerados inferiores: $\sin$ educación, sin valores, sin organización política, económica, etc. (Boivin; Rosato; Arribas, 2002: 27). Desde esta perspectiva, LF puede llenar la falta casi mágicamente, sin fundamentos sólidos: "nunca habían tenido ninguna regla de nada (...) ellos dejan de hacer el mal, pero no se quedan neutros, empiezan a hacer el bien”.

LF aporta las credenciales de acceso a una nueva vida en el encierro, más allá de la práctica deportiva: contención espiritual, asesoramiento legal, mejor alimentación, un pabellón tranquilo, posibilidad de jugar un partido fuera de la prisión, entrenamientos en un gimnasio lujoso y equipado dentro del establecimiento penitenciario; pero, además, aporta alternativas laborales concretas una vez cumplida la condena. A esto se refieren los gladiadores cuando dicen que "el rugby me dio una nueva vida", este discurso aparece destacado en todas las apariciones públicas, en los testimonios de los redimidos por LF, como prueba de su cambio radical. Pero se trata de algo más que de una prueba, se trata de lo que podemos analizar como reciprocidad, ya que una de las principales tareas de los redimidos es dar testimonio de su cambio. Este contenido discursivo redentor en intervenciones públicas en medios masivos es rápidamente captado por los y las periodistas, que muchas veces van incluso más allá; por ejemplo, el conductor de un programa televisivo que preguntó a uno de los gladiadores cuánto hizo sufrir a su familia, a fin de que la redención fuera 
actualizada in situ, en cámara. Lo complementa el discurso meritocrático adoptado irreflexivamente por los beneficiarios, como el de uno de los gladiadores que se encuentra actualmente en libertad: "alternativas hay, hay que buscarlas, enfrentar la vida, que es dura, pero bueno, nadie te regala nada, hay que ganarse las cosas"; "volver a robar siempre es la primer alternativa que tenés, siempre están los malos ahí afuera"; "[en] LF nos dieron valores y otro estilo de vida".

Por su parte, referentes de LF retoman estos discursos para comunicar resultados a sus fuentes de financiación. Desde un discurso de coaching empresarial, aseguran que "el rugby bajó mucho el índice de violencia"; incluso cuantifican ese resultado: "tenemos un índice de reincidencia del $5 \%$ "; "[en nuestro territorio] tenemos muy buenos resultados". Pero, aún más importante, lo que comunican es redención a partir del cambio radical de las personas detenidas y a través de esta segunda oportunidad que constituye ser un gladiador. En términos simples, antes eran malos, ahora son buenos: "Dar segundas oportunidades a personas que se equivocaron feo, esto no significa que salgan ni un día antes, van a pagar la pena que tengan que pagar".

La redención es actualizada en cada aparición pública de los gladiadores: "Gracias al rugby nosotros podemos tener buenos pensamientos, y nos ayuda a poder mostrarle a las personas que antes éramos malos y hoy somos mejores personas. Gracias al rugby podemos ser ejemplo el día de mañana", afirma uno de sus capitanes. La transformación personal, hecha de redención (y previo acceso a la posibilidad de ser redimido) habilita una nueva vinculación con la sociedad y a lugares de trabajo en blanco: "Yo estoy haciendo lo mejor para mí, para LF, para no permanecer caídos (...) para que los [gladiadores] que vean este video vean que se puede", ejemplifica un integrante del equipo que está actualmente en libertad y trabajando en una estación de servicio de la empresa YPF.

Además del acceso a trabajo en blanco, hay otro trabajo al que los redimidos deben dedicar tiempo: el voluntariado en LF, los colaboradores son parte fundamental del desarrollo del proyecto. Los voluntarios colaboran de diferentes formas, todas tienen como objetivo conseguir adeptos. Se trata de dos tipos de actividades que consideramos semejantes a la tarea evangelizadora: una es llevar la palabra y las historias de vida de los redimidos a otras cárceles para captar nuevos gladiadores; la otra se dirige a los empresarios, quienes constituyen el sostén de La Fundación, en eventos vinculados al mundo del rugby, donde los redimidos asisten para dar testimonio de vida: "Fui a dar mi testimonio de vida a Alumni ${ }^{12} \mathrm{y}$ ahí conocí a Pedro. Él me preguntó si estaba trabajando y me dijo si quería un trabajo en blanco".

12. La Asociación Alumni es un club de rugby de la Argentina, con sede en Buenos Aires, creado en 1951 por iniciativa del Buenos Aires English High School. 
Ahora bien, ¿cuál es el papel que LF construye respecto a los servicios penitenciarios? En principio, se sostiene un vínculo simbiótico, de necesidad mutua entre la fundación y el servicio. Referentes y equipo necesitan que "les bajen a los pibes" para los entrenamientos, que estos pibes tengan un tratamiento especial, de modo que tienen muchas más horas de esparcimiento que las personas alojadas en otros pabellones. Por otro lado, el servicio se beneficia con la buena conducta de este pabellón y, claro, con la delegación de actividades tratamentales en una fundación con la que además coinciden en muchas de sus valores.

Pero esa relación entre LF y el servicio penitenciario tuvo que ser construida en el tiempo. Al comienzo había distancia, como afirmaba, en televisión, uno de sus referentes:

Periodista: Ahora, ¿qué te decía el director de la cárcel, los penitenciarios, el Estado, bah...?

Referente: Cero. Nos querían sacar. Lo que pasa es que nadie entra a estos lugares y los dueños son los penitenciarios, ellos hacen y deshacen y si vos empezás a dar vueltas por ahí, ves qué hacen y qué no hacen, ves todo... entonces pasás a ser un grano ahí.

Una vez que comenzaron a ser visibles resultados como: cada vez más pibes entusiasmados con el rugby, pabellón tranquilo, repercusión en los medios y visita al Papa (en la que el SPB también formó parte de la comitiva), la distancia desapareció y LF tuvo abiertas las puertas del complejo penitenciario. LF construyó la cancha de pasto sintético (la única dentro de un complejo penal en Argentina) y un gran gimnasio con aparatos modernos, estos elementos estéticamente devuelven una imagen modernizada que modifica la anterior, mucho más asociada a cierta decadencia y precariedad de los establecimientos penitenciarios del SPB.

Esta modernización alcanza a la imagen de los/as agentes penitenciarios/as, también devaluada, cuando son invitados a participar en videos institucionales. Por ejemplo, en un video institucional en el que LF desea felices fiestas (en 2019), se pueden ver trabajadores penitenciarios diciendo "gracias por acompañarnos un año más", participando activamente como parte integrante del programa que la fundación despliega. De esta manera, son incluidos en el proyecto como un colaborador más, aceptando, del mismo modo que las personas detenidas, su parte en el pacto tácito de reciprocidad.

Por otro lado, LF significa resultados concretos en términos de abordaje no penitenciario de actividades tratamentales, a juzgar por las estadísticas (propias) que exponen; pero también significa prestigio, apoyo de un sector del empresariado y de un sector judicial, en suma: significa poder emanado de un sector hegemónico de la sociedad. Con estas características, no asombra que el servicio penitenciario 
FIGURA 2 Cancha de pasto sintético de LF

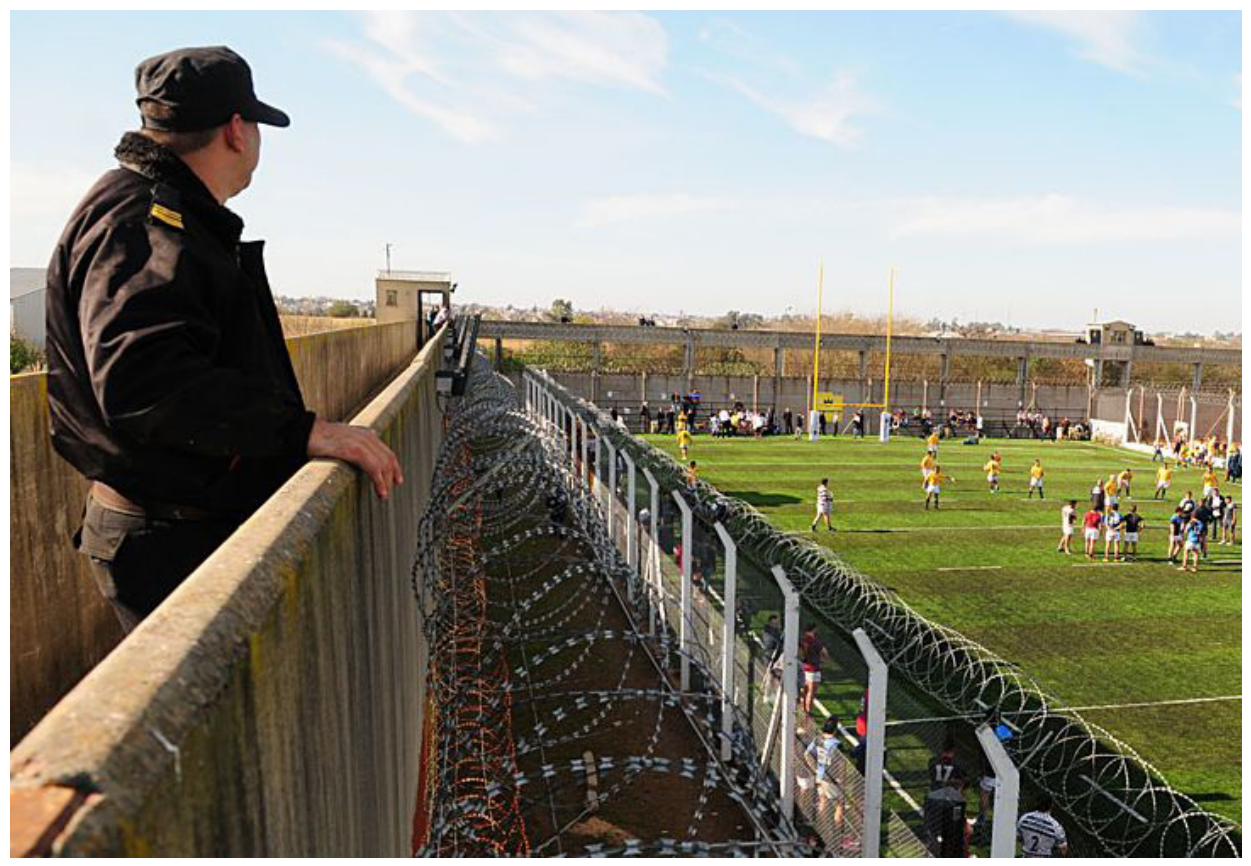

Fuente: perfil.com

no solo delegue parte de sus tareas en esta fundación, sino que además participe activamente en sus acciones: acompañando todos sus eventos, apareciendo en los videos producidos por LF, participando en las fechas y celebraciones religiosas del catolicismo (novenas, vía crucis, etc.). Sentirse incluidos en La Fundación los incluye en el marco de la formación completa, que podría constituir un ideal tratamental, ya que existe también coincidencia en cuanto a valores religiosos.

\section{“La ruta de la inclusión”: La Red}

El objetivo de La Red (LR) es generar inclusión socioeconómica de personas privadas de la libertad a través de un proceso participativo que involucra a los entornos directos de dicha población. Conformada en 2018, se enfoca en la "construcción de una red de impacto colectivo capaz de organizar y articular las voluntades de inversión de los actores de los sectores público, privado y social". 
A mediados de 2018, se realizaron las primeras reuniones de más de treinta organizaciones de la sociedad civil, empresas, universidades y entes estatales que conforman LR. El lanzamiento oficial se realizó en junio de 2019. La gran convocatoria fue lograda por sus promotores y también principales referentes: una empresa de gastronomía (EG) y la fundación social de una gran empresa agroexportadora (EA), ambas de origen nacional. Los coordinadores de LR son impulsados por objetivos de responsabilidad social empresarial y recomendaciones internacionales, como se puede observar en la propia descripción que los/as referentes presentaron en esas primeras reuniones.

La EG se presenta como una compañía que cuenta con más de cuarenta años de experiencia en el rubro y que trabaja para incorporar en todos sus procesos de gestión "una perspectiva de sustentabilidad económica, social y ambiental que acompañe el progreso de las personas y de la organización”. Por otro lado, EG describió las características generales de su programa CREER (confianza, respeto, esfuerzo, emprendimiento y responsabilidad). Dicho programa surge por iniciativa de EG y tiene como objetivo la inserción laboral de poblaciones excluidas de este ámbito. Según un directivo de EG, se trata de un proceso que permite que las personas "aseguren, retengan y progresen en empleos adecuados y, en consecuencia, impulsa su integración o reintegración en la sociedad". EG se orienta, en ese sentido, con base en la recomendación de la Organización Internacional del Trabajo (OIT) para la readaptación laboral, la cual involucra la provisión de servicios profesionales, en particular, de orientación, formación ocupacional y de colocación selectiva. Por su parte, la EA presentó la Plataforma Comunidad como una plataforma metodológica para diseñar e implementar estrategias colaborativas de inversión social, desarrollo territorial e impacto colectivo creada por ella en 2005.

Como en el caso de La Fundación, los números y resultados tienen un lugar destacado en la fundamentación de sus proyectos: la plataforma comunidad ha coordinado proyectos de articulación de impacto económico, social y ambiental, en más de 230 territorios. A diferencia de LF, La Red posee un marco epistemológico explícito y una estudiada metodología que va adecuando a cada proyecto a desarrollar, junto a sus actores involucrados y beneficiarios. Esta operatoria habla de su amplia experiencia en coordinación de redes de organizaciones y años de trayectoria en proyectos de impacto social planificados al detalle antes de ser lanzados.

Otra diferencia es el posicionamiento profesional/racional que sustenta LR sin el elemento religioso, que en el caso de La Fundación constituye un pilar fundamental para el logro de redención de las personas detenidas. La Red, por su parte, sustenta su nivel de conocimiento y profesionalismo en su capacidad organizativa, de formación ocupacional y de colocación selectiva, elementos centrales en la especificidad del 
aporte que realizan a la sociedad. Se despliega entonces un diseño metodológico sofisticado para cada proyecto que encara. En ese sentido, LR propone un Modelo de Impacto Colectivo para la Inclusión Socioeconómica de Personas Privadas de la Libertad, conformado por tres componentes: desarrollo de capacidades, desarrollo económico y una red de impacto colectivo, los cuales se relacionan entre sí a partir de dos ejes transversales: acceso a justicia y derechos, y educación e inclusión financiera. En el complejo modelo se evidencia la capacidad organizativa mencionada.

El desarrollo de capacidades busca brindar herramientas teórico-prácticas que posibiliten ampliar el espectro de oportunidades presentes y futuras de la población carcelaria y su entorno directo a través del desarrollo y fortalecimiento de habilidades socioemocionales, capacitaciones en oficios y programas educativos. En cuanto al desarrollo económico, LR se orienta a brindar herramientas y fortalecer capacidades específicas para la inserción económica de las personas detenidas, liberados y sus familiares a través de la inserción laboral en el mercado de trabajo o mediante los emprendimientos individuales o asociativos.

FIGURA 3 Presentación institucional de LR

\section{LA RUTA DE LA INCLUSIÓN}

Una guía orientadora para la acción colectiva

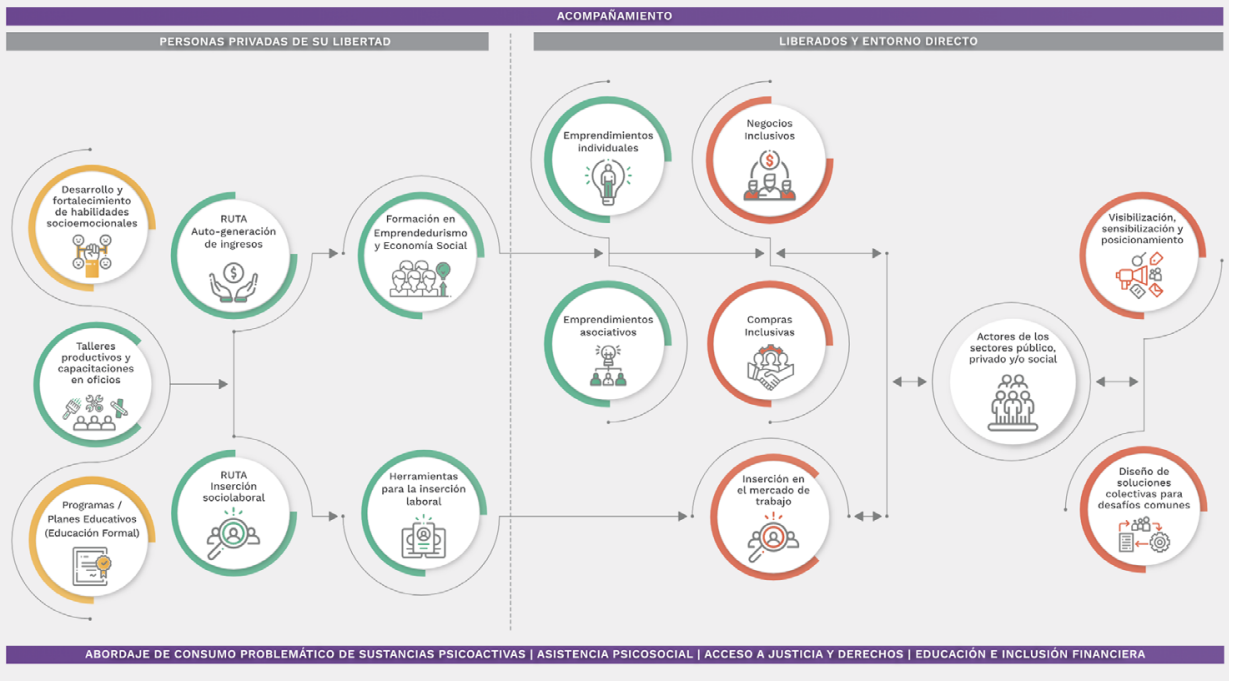


Como red de impacto colectivo, proponen diseñar un plan de cogestión y coinversión que posibilite implementar una estrategia de abordaje articulado entre los sectores público, privado y social (ONG, fundaciones, etc.) a fin de generar mayores oportunidades de inserción socioeconómica.

Ahora bien, la sofisticada modelización tiene como herramientas fundamentales los pilares del tratamiento penitenciario dentro del componente desarrollo de capacidades, orientadas a educación y trabajo, formación en talleres productivos y capacitaciones en oficios y programas educativos. En cuanto al deporte y la espiritualidad, aparecen dentro del mismo componente como habilidades socioemocionales: "tales como: autoestima, cooperación, trabajo conjunto, coexistencia, identidad individual y colectiva, empatía, dinámicas de relacionamiento, entre otras", concebidas como condición para generar un proceso de inclusión social de personas privadas de la libertad.

El componente desarrollo económico retoma las habilidades fortalecidas en el componente anterior y adiciona el desarrollo de capacidades para la inserción económica, ubicándose así este componente en un nivel superior de aplicación de las habilidades adquiridas.

En el componente red de impacto colectivo, aparece la vinculación multiactoral de los "sectores público, privado y social" para la generación conjunta de oportunidades. Aquí se diseña la articulación entre los actores estatales, empresariales y sociales, todos ellos con relevancia equivalente, bajo la coordinación de los referentes de La Red: EG y EA.

Las oportunidades ocupan un papel protagónico. Mientras que en el caso de La Fundación se habla de "segunda oportunidad", incorporando tácitamente una primera, malgastada en el mal por el preso, y una segunda que será la oportunidad de redimirse a través del bien, ambas se circunscriben en un marco más amplio, religioso, bajo los principios y preceptos del catolicismo. En La Red se habla de oportunidades, en plural, desde un discurso de corte profesional, propio de las áreas de responsabilidad social empresarial.

En el siguiente fragmento de una reunión de LR, realizada en octubre de 2018, se argumenta la estrategia multiactoral del proyecto, asociada a un tipo de trabajo conjunto: "En este marco, el éxito en la implementación de un proceso de escala que apunte a la inclusión socioeconómica de la población privada de su libertad depende del desarrollo de una estrategia articulada entre múltiples actores y la necesidad de trabajar desde una perspectiva multidimensional e integral".

La Fundación no expone a su red (que incluye empresas, funcionarios públicos, universidades, etc.) en la planificación de sus acciones, por lo que actúa más a modo de patrocinadores o desde la colaboración, a veces financiera, del proyecto. Por el 
contrario, La Red, de la cual LF forma parte, basa su planificación y diseño en la articulación multiactoral. Más allá de esta diferencia estratégica, ambos son actores protagónicos que intervienen en el campo carcelario y poscarcelario, que se presentan con propuestas integrales y con intenciones superadoras con respecto a las que desarrolla el tratamiento penitenciario. En este sentido es que se miden cada una de las acciones para luego destacar los resultados en sendas páginas web, los cuales suelen ser mucho más alentadores que los que puedan mostrar los servicios penitenciarios.

Cabe señalar que ambas experiencias cuentan con vastos recursos, en términos presupuestarios, de contactos y de capital organizativo que manejan y orientan en función a sus objetivos. Ambas propuestas ponen en el centro a sus redes propias de actores y, de este modo, desconocen el papel de coordinación integral que debe tener el Estado en la gestión penitenciaria, a partir no solo de su autopostulación para el desarrollo de tareas tratamentales, sino, más aún, del consecuente desplazamiento de lo público que, persiguiéndolo o no, consiguen.

\section{Conclusiones}

La tarea del Estado en materia de política penitenciaria tiene dos objetivos fundamentales: promover valores trascendentes articulando cuestiones de la seguridad y la defensa de la sociedad, y velar por la dignidad de las personas privadas de libertad y su derecho a contar con oportunidades para reintegrarse al seno de la comunidad como personas útiles para sí mismas, para su familia y para la sociedad.

Sin embargo, a partir del caso del complejo penitenciario analizado, se pone en evidencia la no identificación en territorio bonaerense de una política pública que produzca avances efectivos sobre el discurso resocializador; aunque en las narrativas ligadas al campo penal persiste este ideal original: figura en las normativas internacionales y en las leyes locales, en los planes de reforma de los servicios penitenciarios, en las publicaciones internas del SPB y aparece también en los dichos de los miembros de esta fuerza. La forma de resolver esta controversia ha sido entonces la incorporación generalizada y acentuada, en particular en los últimos años, de organizaciones de la sociedad civil a la vida cotidiana de la cárcel para desarrollar actividades que luego son calificadas y asignadas por el discurso penitenciario como tratamentales.

Desde sus actividades en las cárceles, tanto La Fundación como La Red dicen orientarse al desarrollo de "habilidades técnicas y socioemocionales" que tienen por finalidad preparar a las personas detenidas para la vida laboral y la interacción social. $\mathrm{Al}$ hacerlo intervienen no solo en la resocialización laboral de los detenidos, sino también buscan transformarlos en "mejores personas, equilibradas, financieramente 
autosuficientes, moralmente capaces", según las palabras de sus voluntarios. Cada organización lo hace desde su propia cosmovisión, pero compartiendo propuestas integrales desplegadas a través de prácticas como las descritas, asociadas a aspectos deportivos, educativos, religiosos y laborales.

Dentro de las corrientes criminológicas sobre el desistimiento delictivo (Burnett, 1992; Laub; Sampson, 2003; Maruna, 2001), delineadas a partir de la experiencia en cárceles en países centrales mayormente anglosajones, la teoría del Apoyo Social (Cullen, 1994) sostiene que el proceso que permite a las personas mantenerse fuera del delito exitosamente empieza como consecuencia de la formación de nuevos vínculos sociales y suele depender del apoyo que reciban de las redes primarias, sociales o comunitarias, como las que ofrecen La Fundación y La Red. La cantidad real o percibida de apoyos recibidos determinará la posibilidad de afrontar las adversidades que supone alcanzar el desistimiento (Luna de la Mora, 2017).

Las propuestas que ofrecen LF y LR vienen acompañadas de la transmisión de una serie de valores hegemónicos, ligados mayormente a una ideología de élite (Canelo; Castellani; Gentile, 2018), desde la que se propone el autocuidado, la autosustentación económica y una redención individual con arrepentimiento visible, que denote la transformación subjetiva. La persona que se incorpora a estos programas accede a información que le permite conocer no solo cómo armar estratégicamente un curriculum vitae o cómo usar una tarjeta de débito, sino también qué es trabajar en una empresa, qué se espera de un buen trabajador, qué hacer y dejar de hacer (rutinas ligadas al esfuerzo, el ahorro, la generación de confianza en los otros, el respeto a la autoridad, etc.). Se perfila así un tipo de ciudadano civilizado, se espera una participación activa; el beneficiario debe no solo sentirse vinculado, sino demostrarlo con cierta intensidad: dando testimonio de su cambio, pasando a ser voluntario en un programa, dando signos concretos de su adhesión a la nueva vida otorgada por la organización. El contrato tácito implica la aceptación por parte de la persona detenida de un paquete de normas, valores y prácticas, en suma: la construcción narrativa de un nuevo estilo de vida.

Siguiendo a Maruna (2001: 87), "el guión de redención comienza estableciendo la bondad y la convencionalidad del narrador, una víctima de la sociedad que se ve involucrada en la delincuencia (...) para lograr cierta forma de poder sobre circunstancias por lo demás sombrías (...). Pero con la ayuda de cierta fuerza externa, alguien que creyó en el ex delincuente, el narrador puede lograr lo que siempre quiso ser. Dueño de un nuevo poder, ahora busca devolver algo a la sociedad como muestra de gratitud". La persona puede no estar de acuerdo con muchas de las disposiciones, por ejemplo las religiosas o, incluso, con la práctica deportiva, pero el beneficio -sea este la redención o el tránsito por la ruta de la inclusión- lo vale, 
aunque signifique continuar sujeto a esta nueva narrativa y sus mandatos, incluso una vez fuera de la cárcel.

El papel otorgado al Estado por este tipo de intervenciones es secundario. La escala de tratamiento propuesta es primeramente individual y basada en una lógica meritocrática mediante la cual el sujeto decide libremente su propio destino dentro de los marcos de referencia propuestos por este tipo de redes de apoyo. Sin embargo, para el SPB es también una oportunidad, en este caso de modernización, y la posibilidad de mostrar una nueva imagen a la sociedad, más allá de la de trabajadores devaluados de un ámbito particular: "un lugar social de un casi nulo prestigio y a la vez blanco de mucha atención por parte de la opinión pública. También objeto de continuo escrutinio público en vista de las formas actuales de su funcionamiento que dejan las puertas abiertas a desmanes, fugas y sobre todo, motines" (Kalinsky, 2008:45). De esta forma, se muestran trabajando en pos de la ampliación de un conjunto definido de derechos -ligados más bien al desarrollo de aspectos educativos, laborales, culturales y económicos-, a través de sus alianzas con organizaciones de la sociedad civil, asumiendo como propios, acríticamente, sus objetivos, actividades y logros; soslayando, al mismo tiempo, otro tipo de derechos fundamentales bajo la órbita de su competencia.

En ese sentido, a propósito del Estado ético y de la cultura, Gramsci (1997: 154) expresa:

cada Estado es ético en cuanto una de sus funciones más importantes es la de elevar a la gran masa de la población a un determinado nivel cultural y moral, que corresponde a las necesidades de desarrollo de las fuerzas productivas y, por consiguiente, a los intereses de las clases dominantes. La escuela como función educativa positiva y los tribunales como función educativa represiva y negativa son las actividades estatales más importantes en tal sentido. Pero, en realidad, hacia el logro de dicho fin tienden una multiplicidad de otras iniciativas y actividades denominadas privadas, que forman el aparato de la hegemonía política y cultural de las clases dominantes.

Uno de los riesgos de esta forma de gestionar las cárceles está relacionado directamente con la denominada captura de la decisión estatal, que se traduce en pérdida de autonomía del Estado (Castellani, 2018). Específicamente se trata de un riesgo de apropiación cultural: "por la cual las empresas se benefician de la acción de las agencias públicas porque los funcionarios comparten un mismo conjunto de creencias y visiones sobre el sector en cuestión, un ethos favorable al mercado" (Castellani, 2018: 56). De hecho, los integrantes de las organizaciones, actores no estatales, al participar en estos programas son retribuidos de muchas formas: con exenciones impositivas, promociones de sus marcas y el blanqueamiento de imagen 
de la mano de la responsabilidad social empresarial. Pero, además, estas actividades les resultan instancias donde propugnan las propias creencias: la perspectiva desde la cual se posicionan y trabajan. Resulta una forma muy difusa, pero no por eso menos importante, de avance sobre las decisiones estatales, en la que el paso coyuntural por el sector público genera condiciones estructurales propicias para el logro de intereses particulares. Así "se conectan directamente los espacios de la administración pública y privada y se van debilitando los grados de autonomía estatal" (Castellani, 2018: 61).

Los gobiernos formulan e implementan constantemente políticas públicas que, por definición, deberían procurar el bienestar de la sociedad en su conjunto, perseguir el interés general y producir bienes públicos de calidad. Este artículo permite pensar la práctica penitenciaria en su forma específica y contextual de producción, dando cuenta de las negociaciones ideológicas y disputas de sentidos que tienen lugar en este campo en términos de transmisión de valores sociales, más allá de la formalidad del Estado. A través del estudio de este caso, analizamos los márgenes específicos donde conviven la agencia de actores estatales y no estatales en el ejercicio del tratamiento penitenciario, dando cuenta de su productividad en el sostenimiento de la propia fuerza a cargo de la gestión de las cárceles bonaerenses, sin la cual la institución se vería impedida para llevar a cabo una de sus funciones principales. Si además tenemos en cuenta, según se ha descrito, que las tareas de control y seguridad son delegadas a la población detenida, el Servicio Penitenciario Bonaerense parece convertirse en un mero gestor, restringido a vehiculizar las prácticas de otros actores del campo.

\section{Referencias}

Abrams, Philip (1988). Notes on the Difficulty of Studying the State. Journal of Historical Sociology, 1(1), 58-89.

Andersen, María Jimena (2012). Los pabellones evangelistas en las cárceles del Servicio Penitenciario Bonaerense. Antagonismos entre las perspectivas micro y macrosociológica en el estudio de la prisión. En Seminario de estudios comparados sobre las estrategias del gobierno de la cárcel neoliberal en Argentina y en Francia (pp.188-205), editado por Grupo de Estudios sobre Derecho Penal y Derechos Humanos. Buenos Aires: Universidad de Buenos Aires.

Ángel, Luis (2015). La política acá la hacemos nosotros: relaciones de gobernabilidadyjerarquización en una cárcel bonaerense (Tesis de licenciatura). Universidad Nacional de San Martín, Instituto de Altos Estudios Sociales, San Martín. Recuperado de https://ri.unsam.edu.ar/ bitstream/handle/123456789/277/TLIC_IDAES_2015_ALA.pdf? sequence=1\&isAllowed =y 
Antillano, Andrés (2015). Cuando los presos mandan: control informal dentro de la cárcel venezolana. Espacio Abierto, 24(4), 16-39.

Barbosa, Antonio (2005). Prender e dar fuga: biopolitica, sistema penitenciario e trafico de drogas no Rio de Janeiro (Tesis doctoral). Universidade Federal do Rio de Janeiro, Programa de Pós-Graduação em Antropologia Social, Rio de Janeiro.

Beckett, Katherine; Sasson, Theodore (2004). The Politics of Injustice. Thousand Oaks: Sage.

Biondi, Karina (2018). Proibido roubar na quebrada, territorio, hierarquia e lei no PCC. Sao Paulo: Terceiro Nome.

Boivin, Mauricio; Rosato, Ana; Arribas, Victoria (2002). Constructores de otredad. Una introducción a la antropología social y cultural. Buenos Aires: EUDEBA.

Boltanski, Luc (2000). Amor y justicia como competencias. Tres ensayos de sociología de la acción. Buenos Aires: Amorrortu.

Brandariz-García, José Ángel; Castro-Liñares, David (2014). The "Great Recession" and Criminal Justice: The Value of Scarcity? Howard League What is Justice? Working Papers The Howard League for the Penal Reform, 20, 1-14.

Brardinelli, Rodolfo; Algranti, Joaquín (2013). La re-invención religiosa del encierro: hermanitos, refugiadosy cachivaches en los penales bonaerenses. Bernal: Universidad Nacional de Quilmes.

Burnett, Ross (1992). The Dinamics of Recidivism. Oxford: Oxford Centre for Criminological Research.

Caimari, Lila (2004). Apenas un delincuente. Crimen, castigo y cultura en la Argentina, 1880-1955. Buenos Aires: Siglo XXI.

Canelo, Paula; Castellani, Ana; Gentile, Julia (2018). Articulación entre elites económicas y elites políticas en el gabinete nacional de Mauricio Macri (2015-2018). En Elites y captura del Estado: controly regulación en el neoliberalismo tardio (pp.117-135), compilado por Daniel García-Delgado; Cristina Ruiz del Ferrier; Beatriz de Anchorena. Buenos Aires: Flacso.

Castellani, Ana (2018). Lobbies y puertas giratorias. Los riesgos de la captura de la decisión pública. Nueva Sociedad, 276, 48-61.

Cefaï, Daniel (2003). Acción asociativa y cuidadanía común. ¿La sociedad civil como matriz de la res publica? En Aprendiendo a ser ciudadanos. Experiencias sociales y construcción de la ciudadanía entre los jóvenes (pp. 91-115), editado por María Luz Morán; Jorge Benedicto. Madrid: Instituto de la Juventud.

Cerbini, Francesca (2012). La casa de jabón. Etnografía de una cárcel boliviana. Barcelona: Bellaterra. 
Chauvenet, Antoinette (2006). Privation de liberté et violence: le despotisme ordinaire en prison. Déviance et Société, 30, 373-388.

Clemmer, Donald (1968). The Prison Community. University of Minnesota: Holt, Rinehart and Winston.

Clifford, James (1999). Itinerarios transculturales. Barcelona: Gedisa.

Corcuff, Philippe (1998). Las nuevas sociologías. Construcciones de la realidad social. Madrid: Alianza.

Cullen, Francis (1994). Social Support as an Organizing Concept for Criminology: Presidential Address to the Academy of Criminal Justice Sciences. Justice Quarterly, 11(4), 527-559.

Darke, Sacha (2013). Inmates governance in Brazilian prisons. Howard Journal of Criminal Justice, 52(3), 272-284.

Daroqui, Alcira (coord.), (2014). Castigar y gobernar. Hacia una sociología de la cárcel. La gobernabilidad penitenciaria bonaerense. La Plata: CPM/GESPyDH.

Das, Veena; Poole, Deborah (2008). ¿Dónde están los márgenes del Estado? Cuadernos de Antropología Social, 27, 53-62.

Di Próspero, Carolina (2017). Antropología de lo digital: construcción del campo etnográfico en co-presencia. Virtualis, 8(15), 44-6o. Recuperado de http://www.revistavirtualis.mx/ index.php/virtualis/article/view/219.

Feeley, Malcom; Simon, Jonhatan (1995). La nueva penología. Notas acerca de las estrategias emergentes en el sistema penal y sus implicaciones. Delito y Sociedad, 6/7, 33-57.

Ferguson, James; Gupta, Akhil (2002). Spatialating States: Towards an Ethnography of Neoliberal Governmentality. American Ethnologist, 29(4), 981-1002.

Galvani, Iván (2010). Ubicando a un preso en un pabellón. Relaciones de poder entre personal e internos de una unidad penitenciaria de la Provincia de Buenos Aires. Trabajo presentado en VI Jornadas de Sociología de la Universidad Nacional de La Plata, La Plata, Argentina. Recuperado de https://www.aacademica.org/ooo- 027/46o.pdf

Garland, David (2005). La cultura del control. Crimeny orden social en la sociedad contemporánea. Barcelona: Gedisa.

Goffman, Irving (2001). Internados. Ensayos sobre la situación social de los enfermos mentales. Buenos Aires: Amorrortu.

Gómez-Cruz, Edgar; Ardèvol, Elisenda (2013). Ethnography and the Field in Media(ted) Studies: A Practice Theory Approach. Media Ethnography, 9(3), 27-46. 
Gramsci, Antonio (1997). Notas sobre Maquiavelo. Sobre la política y sobre el Estado moderno. Buenos Aires: Nueva Visión.

Gual, Ramiro (2016). "Prisión depósito" en Argentina. Del "cambio epocal catastrófico" a la “economía mixta del encierro". En Privación de la libertad. Una violenta práctica punitiva (pp. 297-325), compilado por Gabriel Anitua; Ramiro Gual. Buenos Aires: Didot.

Kalinsky, Beatriz (2008). El agente penitenciario: la cárcel como ámbito laboral. Runa, 28, 4357. Recuperado de http://www.scielo.org.ar/pdf/runa/v28/v28a03.pdf

Laub, John; Sampson, Robert (2003). Shared Beginnings, Different Lives. Delinquent Boys to Age 70. Cambridge: Harvard University Press.

Lombraña, Andrea; Ojeda, Natalia; Nogueira, Gonzalo (2019). Políticas de seguridad y gestión carcelaria. Discursosy prácticas penitenciarias en territorio bonaerense. Trabajo presentado en XIV Congreso Nacional de Ciencia Política "La política en incertidumbre. Reordenamientos globales, realineamientos domésticos y la cuestión de la transparencia”, San Martín, Argentina.

Luna de la Mora, Tadeo (2017). Desistimiento delincuencial y prevención el delito. Presentación y apuntes de una corriente en criminología para favorecer la seguridad. En La ciencia criminológica en la prevención y sus campos de aplicación (pp. 177-202), coordinado por Gil David Hernández Castillo; Carla Monroy Ojeda. México: Flores.

Manchado, Mauricio (2015). Las insumisiones carcelarias. Procesos comunicacionales y subjetivos en la prisión. Rosario: Río Ancho.

Martínez, María José (2004). Expedientes. Sistemas Judiciales, 7, 4-7.

Maruna, Shadd (2001). Making Good. Washington DC: APA.

Miguez, Daniel (2007). Reciprocidad y poder en el sistema penal argentino. Del "pitufeo" al motín de Sierra Chica. En En los márgenes de la ley. Inseguridady violencia en el cono sur (pp. 23-46), compilado por Alejandro Isla. Buenos Aires: Paidós.

Miguez, Daniel (2008). Delito y cultura. Los códigos de la ilegalidad en la juventud marginal urbana. Buenos Aires: Biblos.

Mouzo, Karina (2014). Actualidad del discurso resocializador en Argentina. Crítica Penal y Poder, 6, 178-193.

Mouzo, Karina; Ríos, Alina (2018). Programas de atención psiquiátrica y gobierno del espacio carcelario en el Servicio Penitenciario Federal argentino. Cuadernos de la Facultad de Humanidades y Ciencias Sociales, 53, 13-39. 
Nogueira, Gonzalo (2015). El orden indecidible. Configuraciones del ordenamiento social en una cárcel del conurbano bonaerense (Tesis doctoral). Universidad Nacional de San Martín, Instituto de Altos Estudios Sociales, Doctorado en Sociología. Recuperado de https:// ri.unsam.edu.ar/handle/123456789/116

Nunes, Camila (2011). Estado e PCC em meio às tramas do poder arbitrário nas prisões. Tempo Social, 23, 213-233.

Nuñez, Jorge (2007). Las cárceles en la época del narcotráfico: una mirada etnográfica. Nueva Sociedad, 208, 103-117.

Pratt, Mary Louise (1992). Imperial Eyes. Travel Writing and Transculturation. London: Routledge.

Rosas, Damián Jesús (2015). El mundo evangélico en la cárcel. Un estudio etnográfico sobre un pabellón evangélico de la Unidad Penitenciaria No 48 de San Martín (Tesis de licenciatura). Universidad Nacional de San Martín, Instituto de Altos Estudios Sociales.

Roseberry, William (1994). Hegemony and the language of contention. En Everyday Forms of State Formation: Revolution and the Negotiation of Rule in Modern México (pp. 117-139), editado por Gilbert M. Joseph; Daniel Nugent. Durham: Duke University Press.

Sozzo Máximo (2007).¿Metamorfosis de la prisión? Proyecto normalizador, populismo punitivo y prisión-depósito en Argentina. Urvio, 1, 41-44.

Sykes, Gersham (2017). La sociedad de los cautivos. Estudio de una cárcel de máxima seguridad. Buenos Aires: Siglo XXI.

Tiscornia, Sofía (2008). Activismo de los derechos humanosy burocracias estatales. El caso Walter Bulacio. Buenos Aires: Editores del Puerto.

Weber, Max (1996). Economía y sociedad. México: FCE.

Western, Bruce (2006). Punishment and Inequality in America. New York: Russell Sage Foundation.

Yangilevich, Melina (2017). Vínculos complejos: cárcel, Estado y sociedad en la provincia de Buenos Aires (Argentina) durante la segunda mitad del siglo XIX. Claves, 3(4), 165-190. 